\title{
CORRESPONDENCE
}

The Review of 'Kerrich' in Vol. vi

The Editor,

The fournal of the Institute of

2 fune 1947

Actuaries Students' Society

Dear Sir,

In his review of Mr Kerrich's An Experimental Introduction to the Theory of Probability on p. I89 of Vol. vi, H. W. H. seems momentarily to have forgotten the circumstances, described in the Preface, under which the book was written. Mr Kerrich, having chosen Copenhagen for his place of study during a year's leave from the Witwatersrand, was caught by the German invasion; he and his wife endured five years of internment. It says much, I think, for his spirit and character that he performed the experiments he has described and wrote a book under those conditions, staving off his personal ennui by performing a service to students. He says in his Preface 'a little ground is covered thoroughly' and claims no more.

Yours faithfully,

Mathematical Institute

A. C. AITKEN

I6 Chambers Street

Edinburgh I

Worger's Rule for Approximate Yields

The Editor,

The Fournal of the Institute of

I7 April 1947

Actuaries Students' Society

Dear Sir,

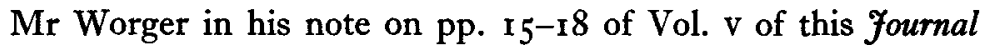
gives a brilliant rule for finding the approximate yield on a Bond, allowing for income tax, but his exposition seems to mask the very simple relation on which his rule is based. Let us find the period $\mathrm{N}$ which gives the true equivalent gross yield when tables of Bond Values are entered at the gross nominal rate of interest. 
We have $k=(g-i) a_{\text {ST }}=(g / i-1)\left(1-v^{N}\right)$, where $v=1 /(1+i)$. Also by definition of $i$

$$
\begin{aligned}
k & =[g(\mathrm{I}-t)-i(\mathrm{I}-t)] a_{\bar{n} \mid}^{\prime}, \text { where } a_{\bar{n}}^{\prime} \text { is calculated at rate } i(\mathrm{I}-t) \\
& =(g / i-1)\left(\mathrm{I}-\mathrm{V}^{n}\right), \text { where } \mathrm{V}=\mathrm{I} /(\mathrm{I}+\overline{\mathrm{I}-t i}) .
\end{aligned}
$$

Hence $v^{\mathrm{N}}=\mathrm{V}^{n}$,

$$
\mathrm{N}=n \log (\mathrm{I}+\overline{\mathrm{I}-t i}) / \log (\mathrm{I}+i)=n(\mathrm{I}-t)\left(\mathrm{I}+i t / 2-i^{2} t(5-4 t) / n \ldots\right),
$$

from which it is clear that the true period $N$ with which to enter the tables is not much different from the period $n(\mathrm{x}-t)$ given by Mr Worger's rule. In his Addendum Mr Worger shows that

$$
\log _{e}(\mathrm{I}+\overline{\mathrm{I}-t} i)>(\mathrm{I}-t) \log _{e}(\mathrm{I}+i) \text {, }
$$

i.e. that $\mathrm{N}$ is always greater than $n(\mathrm{I}-t)$.

It might be pointed out that Mr Worger's formula for the maximum numerical error arising from the use of his rule is not always true when $k$ is negative and examples illustrating this are not difficult to devise. This is because Mr Worger takes his error from the formula $i+\epsilon=g-k / a_{\overline{n(1-t)}}$, where $a_{\overline{n(1-i)} \mid}$ is calculated at rate $i$, whereas strictly speaking $i+\epsilon$ should be used. When $k$ is positive the numerical value of Mr Worger's $\epsilon$ is greater than the true error and his formula for the limit error holds.

Yours faithfully,

Assurance Buildings

A. W. JOSEPH

Steelhouse Lane

Birmingham 4

\section{The Actuary's Training}

The Editor,

The Fournal of the Institute of

Actuaries Students' Society

I I August 1947 Sir,

The writer of the editorial review of Surrender and Paid-up Policy Values (F.S.S. Vol. viI, p. 49) doubts whether the new series of text-books will prove to be satisfactory material for the training of future actuaries. 